\title{
Anticoagulation in Cerebral Embolism
}

\author{
Edward Bass
}

\begin{abstract}
SUMMARY: A case of presumed anticoagulant induced hemorrhage into infarction is presented along with a retrospective study of 110 cases of cerebral embolus.

An accurate recommendation for the timing of anticoagulation following cerebral embolism hinges on balancing the risk of hemorrhage into infarction against the benefits of early treatment attributed to preventing recurrent embolism. It is felt that the present literature, concepts of pathogenesis and experimental data provide insufficient information to make absolute clinical decisions. The available evidence implies that the risk of further embolic events is three to four times that of hemorrhage into infarction, yet additional randomized prospective studies and better experimental models are needed to establish a valid treatment plan. It may be possible to distinguish separate mechanisms underlying early diffuse hemorrhage into infarction from sudden delayed massive hematoma formation.
\end{abstract}

RÉSUMÉ: Nous présentons un cas d'hémorragie présumément induite par les anticoagulants sur un fond d'infarctus cérébral ainsi qu'une étude rétrospective de 110 cas d'embolie cérébrale.

Lorsqu'il faut recommander le moment propice pour l'emploi d'anticoagulants après une embolie cérébrale, il faut savoir contrebalancer les risques d'hémorragie contre les bénéfices d'un traitement précoce dans le but de prévenir les embolies récurrentes. Nous croyons que la littérature présente, ainsi que les concepts de pathogénèse et les données expérimentales sont insuffisants pour permettre des décisions cliniques absolues. Il semblerait que le risque de réembolie est de 3 à 4 fois plus élevé que celui de l'hémorragie, mais il faudrait des études prospectives contrôlées et de meilleurs modèles expérimentaux pour pouvoir établir un plan thérapeutique valable. Il est possible que des mécanismes distincts sous-tendent l'hémorragie diffuse précoce de l'hématome massif.

Can. J. Neurol. Sci. 1983;10:32-36

A recent population study suggests that 1 out of 6 strokes is embolic in origin (Bharucha et al., 1981). Because embolism is such a common occurrence one would assume that there are well established guidelines for anticoagulant therapy. Whenever a patient presents with a non-septic cerebral embolus of cardiac origin, however, there is invariably much discussion as to the ideal time to begin anticoagulant therapy. Decisions may vary according to the presumed etiology or severity of the lesion. They may be altered by the age of the patient or the results of investigations. An informal poll of practising neurologists revealed a wide variety of recommendations. This uncertainty reflects a lack of readily available data on this subject. A quantitative value for the risk of early recurrent embolism is not generally accepted nor is the risk of early hemorrhage into an area of infarction established. The case history reported below prompted an evaluation of these risks. It also prompted reassessment of the experimental data and a review of the concepts of pathogenesis of anticoagulant induced hemorrhage into the site of embolic infarction.

\section{Case Report}

A 58 year old man with hypertension and cardiac dysrhythmia secon dary to alcoholic cardiomyopathy presented to hospital with dysphasia and right hemiparesis. He was anticoagulated after a lumbar puncture revealed clear CSF. Arteriorgraphy revealed obstruction of the internal carotid artery 2 to $3 \mathrm{~cm}$. above its bifurcation. A radionucleotide scan showed a wedge shaped area of increased uptake in the territory of the left middle cerebral artery. He was treated with heparin and Coumadin. He was convalescing well with controlled anticoagulant levels until the eleventh day of treatment when he suddenly complained of headache, vomited, became stuporous and died. The general autopsy confirmed the diagnosis of alcoholic cardiomyopathy but showed no evidence of mural thrombus. The neuropathological examination revealed a fresh hematoma deep in the left hemisphere with extension into the lateral ventricle. Transtentorial herniation was present. Microscopic examination showed multiple small non-hemorrhagic infarctions in the posterior frontal cortex on the left side. These were estimated to be approximately fifteen days old. Hypertensive vascular changes were absent and atherosclerotic changes were minimal. The neck vessels were not available for examination.

\section{ADDITIONAL CLINICAL MATERIAL}

This case led to a careful search of autopsy records at three McGill University teaching hospitals. 264 cases of spontaneous intracerebral hemorrhage were screened. There were no cases wherein it could be argued that anticoagulants caused hemorrhage into the site of previous embolic cerebral infarction.

In addition, the records of 101 cases of initial cerebral embolus were examined to see if any went on to develop hemorrhage into the site of the infarction. 71 of the patients were treated and none had this complication. Furthermore, none had a recurrence within the first month. In contrast, 3 of 30 untreated patients had a recurrence within one month. Treated patients differed from untreated ones in that they tended to be younger, had milder deficits and had atrial fibrillation most often associated with rheumatic heart disease. The cases were non-randomized and the decision as to anticoagulation was left up to the treating physician.

\section{DISCUSSION}

The above observations suggest that cases of anticoagulant induced hemorrhage into infarction are less

From the Department of Neurosciences, Sir Mortimer B. Davis Jewish General Hospital, Montreal, Quebec.

Received February 18, 1982. Accepted for publication September 20, 1982.

Address reprint requests to' Dr. Edward Bass, Department of Internal Medicine, Division of Neurology, Box 19, University of South Florida, 12901 North 30th Street, Tampa, Florida 33612. 
common than generally suspected. Except for the case reported here, no other examples were found amongst the 71 other treated cases which were reviewed. Of 264 autopsied cases of spontaneous intracerebral hemorrhage; none showed clear evidence of anticoagulant induced hemorrhage into infarction. A careful search of the literature revealed only seven other cases in which the authors considered a hemorrhage into infarction to be the correct diagnosis. (Case records, Mass. Gen. Hosp., 1962; Duff, 1950; Foley, 1955; lizuka, 1972; Stephens, 1954; Wright and Rothman, 1951; Vastola and Frugh, 1959). Only four of these cases had autopsies and only the case reported from the Massachusetts General Hospital was clearly due to a cardiac embolus. This was a 67 year old woman with mitral stenosis and atrial fibrillation. She developed left hemianopsia, facial weakness and hemisensory loss. On day 12 acute left hemiplegia with coma occurred. At post mortem there were old embolic infarcts and a fresh hematoma corresponding to the clinical deterioration on day 12 .

It was surprising that so few verified cases could be identified and this is perhaps why a clear perspective of the problem of embolic cerebral infarction is so difficult to obtain. Accurate diagnosis of the hemorrhage into embolic infarction is limited by difficulty in defining the clinical events. Initial episodes, although suspected to be embolic in origin, are often not confirmed. There may be no clinical evidence of systemic embolism to other sites, and post-mortem examination may not reveal the suspected cardiac thrombosis. Until recently CT scans were not readily available and small hemorrhages might have been unrecognized. Even now identification of an area of infarction does not specify the etiology. Subsequent clinical deterioration in a patient following a presumed embolus might reflect the natural course of an unrecognized hemorrhage, recurrent emboli, the evolution of an infarction or a hemorrhagic complication of anticoagulation. Differentiating these possibilities is still not easily accomplished. The ideal case with an established cardiac source for emboli, sequential CT scans at all stages and autopsy confirmation has not yet been reported. The case described in this report lacked a CT scan prior to anticoagulation. The arteriogram showed no mass effect but might have missed a small hematoma. The occluded vessel was identified but not examined in detail at post mortem.

A crude risk of hemorrhage into embolic infarction can be obtained from studies designed principally to establish the efficacy of treatment. Studies detailing the nature of hemorrhagic complications are listed in table I. In two of these, cases of anticoagulant induced hemorrhage into infarction were reported. However, there was only a limited amount of clinical information to support the diagnosis. Allowing a generous benefit of doubt in favor of implicating anticoagulants, the risk of hemorrhage in the first month would be no greater than 1 to $2 \%$. The most recent of the above reports, (Furlan et al, 1981) documented 50 well studied patients with cerebral embolus in whom CT scans were performed. None of the 39 patients treated with anticoagulants or the 11 untreated patients developed cerebral hemorrhage.
If one considers the problem from another point of view, namely the risk of early recurrent embolism, similar difficulties in interpretation of clinical events are encountered. The principal studies from the literature are listed chronologically in table 2 . These reports frequently fail to identify the etiology of the underlying cardiac disease. Some also lack information concerning the precise type and timing of treatment and they often fail to indicate whether recurrent emboli involve the cerebral or systemic circulations. Despite these limitations, a roughly calculated percentage of recurrent emboli in the first month following cerebral embolism is presented in table 2 . The risk of recurrent embolism is estimated to be about $7 \%$. A comparison of these two risk factors leads to the general conclusion that early treatment with anticoagulants is advisable and that waiting three to four weeks exposes the patient to an increased risk of re-embolism. The results of the above studies demonstrate that treatment with anticoagulants does reduce the rik of recurrent embolism.

Should treatment begin as soon as the diagnosis of cerebral embolism of cardiac origin is established or should it be delayed 24 to 72 hours? To answer this question we must consider the sequence of events which may occur following a cerebral embolus. The hemorrhagic nature of embolic cerebral infarction was emphasized by Fisher and Adams (1951) and Adams and Vander Eecken (1953). They attributed this to the theory of delayed reperfusion of ischemic tissue. Brain tissue, and in particular its vascular tree, becomes ischemic as a result of the initial perfusion block. If obstruction is relieved and blood flow is reestablished, blood components may leak through a damaged vascular bed into brain tissue. A leakage of protein tracers begins within hours of reperfusion and may persist for several weeks (Olsson et al., 1971). These authors also found hemorrhagic areas in some monkeys that were sacrificed 2 to 3 days following removal of a middle cerebral artery clip. The areas of hemorrhage, however, did not correlate well with the leakage of the protein tracer, Evans Blue. These findings suggest that the vascular damage may not be homogeneous and that the hemorrhage may be more than merely the manifestation of severe disruption of the blood brain barrier. Furthermore, it is difficult to postulate the exact site at which anticoagulants might participate in the complex mechanisms of blood brain barrier breakdown. Meyer, (1958) has suggested that anticoagulants promote better collateral flow. Regardless of the mechanism anticoagulant induced weeping of blood through a diffusely damaged vascular bed should result in the production of a hemorrhagic infarct rather than a discreet hematoma. The few reported clinical cases, however, are more suggestive of sudden hematoma formation.

Both types of lesions have been observed by several investigators using an experimental model in which 48 hour autologous clot is injected into the carotid artery of dogs (Frazier et al., 1957; Hill et al., 1955; Moyes et al., 1955; Sibley et al., 1957). The resulting infarcts were even more hemorrhagic when anticoagulants were administered. If anticoagulants were delayed as long as three days following the experimental procedure the infarcts were still more hemorrhagic than controls (Peterman et al., 1960). Even without anticoagulants the infarcts were quite hemorrhagic. 
The hemorrhagic changes were even more extensive than what is usually noted in human embolic infarctions. Whisnant et al (1959) point out that dogs have a particularly rich collateral circulation and that this model utilizes large amounts of friable embolic material. Thus these animal results may not be entirely applicable to the clinical situation.

In the study by Sibley et al (1957) four of the twelve animals who survived more than 24 hours subsequently died suddenly when they appeared to be improving clinically. The lesions were grossly hemorrhagic and three had large hematomas. The formation of a large localized hematoma in animals and humans would suggest rupture of a large vessel, likely of arteriolar size. The formation of a hemorrhagic infarct would suggest generalized seeping of blood from damaged small vessels of capillary or venular size. It may be possible therefore, to identify two types of anticoagulant induced hemorrhage into infarction with different time courses. The likelihood of creating a hemorrhagic infarct may be maximal in the first few days following reperfusion. The development of a massive hematoma appears to be unpredictable with the risk extending to approximately three weeks after the ischemic event.

\section{THER APEUTIC CONSIDER ATIONS}

Views as to the correct timing of anticoagulation following cerebral embolism have varied greatly. The report of the study on antithrombotic therapy chaired by Genton (1977) concluded that "... treatment can begin with oral anticoagulants at the time the patient is seen with anticoagulation achieved three or four days later." Patients with progressing deficits are given heparin. Millikan (1979) recommended immediate intravenous heparin in the face of minimal deficit but a three to five day delay if the deficit is judged severe. Brown and Poskanzer (1969) advocated anticoagulation as soon as the diagnosis of cerebral embolism is established or at least within forty-eight hours. Easton and Sherman (1980) in their recent review of cerebral embolism supported the view of Marshall (1976) in namely immediate therapy so long as the CSF is clear and the clinical deficit is not severe. Each of the above authors recom- mended early treatment but usually added or implied a qualification limiting the speed with which full anticoagulation is accomplished in certain patients.

Several other authors recommend longer delays. Carter (1964) suggested a three week delay. Reichel (1968) recommended a two to three week delay but went on to add that "admittedly there is some risk of further embolization during this period but the risk of massive cerebral hemorrhage is of primary importance, so that the delay in the therapy would seem warranted." Symonds (1956) believed that anticoagulants should be avoided in cerebral embolism and Brain (1957) stated that "it would seem unwise to give anticoagulants within at least three weeks of an attack of cerebral embolism." These opinions were undoubtedly influenced by the experimental data available at the time. The more recent authors have favored a more aggressive approach. The evidence on which one must base these clinical decisions is still incomplete. Series reported prior to the CT scan era are open to criticism since they may include small unrecognized primary hemorrhages. Retrospective nonrandomized studies are also of limited value as there may be a biased selection of certain types of patients for treatment. This type of difficulty was apparent in the review of 101 cases from this institution. Physicians tended to anticoagulate younger patients with mild deficits with a clear history of rheumatic heart disease.

Despite these limitations, clinicians must make therapeutic decisions based on the knowledge available at present. The risk of hemorrhage into embolic infarction in humans is clearly quite low and probably no more than 1 to $2 \%$ in the first month. On the other hand the risk of early reembolism seems to be much greater and is in the range of 7 to $10 \%$. This risk can be reduced by treatment and early anticoagulation is favored. If the CT scan shows no evidence of hemorrhage, intravenous heparin followed by oral anticoagulants should be administered. When a CT scan with infusion reveals a severe breakdown of the blood brain barrier, a more gradual anticoagulation using oral agents would seem appropriate. Finally, when the CT scan shows a definite hemorrhagic infarction it would seem prudent to withhold anticoagulants temporarily until further CT scans indicate resolution of the hemorrhagic component.

TABLE 1

Intracranial Hemorrhage Following Cerebral Embolism

\begin{tabular}{llccc}
\hline Author (Year) & Study Type & Control & Treated \\
& & & All types of & $\begin{array}{c}\text { Suspected } \\
\text { Hemorrhage into } \\
\text { Infarction }\end{array}$ \\
& & & Hemorrage & $1 / 100$ \\
McDevitt (1958) & No Control & & $5 / 100$ & $?$ \\
Wells (1959) & Retrospective & $0 / 53$ & $6 / 29$ & $3 / 55$ \\
Vastola (1959) & No Control & - & $4 / 55$ & $0 / 12$ \\
Baker (1962) & Randomized & $0 / 16$ & $0 / 12$ & $?$ \\
Howell (1964) & Retrospective & $0 / 93$ & $2 / 103$ & $0 / 93$ \\
Carter (1965) & Sequential Years & $0 / 34$ & $0 / 93$ & $0 / 39$ \\
Furlan (1981) & Consecutive & $0 / 11$ & $0 / 39$ & Total 4/260 (1.5\%)
\end{tabular}


TABLE 2

Recurrence of Emboli in Patients Not Treated with Anticoagulants

\begin{tabular}{lcc}
\hline & $\begin{array}{c}\text { Total Recurrence } \\
\text { Cerebral and } \\
\text { Systemic } \\
\text { Patients at Risk }\end{array}$ & $\begin{array}{c}\text { Estimated } \\
\text { 1 Month } \\
\text { Cerebral } \\
\text { Recurrence rate }\end{array}$ \\
\hline Cosgriff (1950, 1953) & $14 / 17$ & $?$ \\
Daley (1951) & $115 / 194$ & $10 \%$ \\
Wells (1959) & $29 / 53$ & $4 \%$ \\
McDevitt (1961) & $* 132 / 47$ & $6 \%$ \\
Baker (1962) & $1 / 9$ & $11 \%$ \\
Szekely (1964) & $14 / 72$ & $5 \%$ \\
Carter (1965) & $7 / 24$ & $?$ \\
Darling (1967) & $102 / 225$ & $8 \%$ \\
Fleming (1974) & $37 / 125$ & $7 \%$ \\
Adams (1974) & $13 / 42$ & $?$ \\
Sage (1981) & $22 / 59$ & $2 \%$ \\
& & Overall 7\% \\
\hline
\end{tabular}

*Refers to embolic events rather than patients

\section{Addendum}

While this paper was in preparation, two additional reports on this topic have appeared in the literature. The conclusions are similar to those presented here. (Furlan, A.J. et al., Neurology 32(3) 280-282, 1982; Koller, R.L., Neurology 32(3) 283-285, 1982).

\section{REFERENCES}

Adams, G.F., Merrett, J.D., Hutchison, W.M., and Pollock, A.M. (1974). Cerebral embolism and mitral stenosis: survival with and without anticoagulants. J. Neurol. Neurosurg. Psych., 37, 378-383.

Adams, R.D., and Vander Eecken, H.M. (1952). Vascular diseases of the brain. Ann. Rev. Med., 4, 213-252.

Baker, R.N., Broward, J.A., Fang, H.C., Fisher, C.M., Groch, S.N., Heyman, A., Karp, H.R., McDevitt, E., Scheinberg, P., Schwartz, W., and Toole, J.F. (1962). Anticoagulant therapy in cerebral infarction. Neurology, 12, 823-835.

Bharucha, N.E., Wolf, P.A., Kanrel, W.B., and McNamara, P.M. (1981). Epidemiological study of cerebral embolism. The framingham study. Neurol., 10, 105.

Brain, R. (1957). Order and disorder in the cerebral circulation. Lancet, 2, 857-862.

Brown, T.R., and Poskanzer, D.C. (1969). Treatment of strokes. NEJM, 281, 594-602, 650-657.

Carter, A.B. (1964). Anticoagulants in rheumatic heart disease. BMJ, 2, 55 .

Carter, A.B. (1965). Prognosis of cerebral embolism. Lancet, 2, 514-519.

Cosgriff, S. (1950). Prophylaxis of recurrent embolism of intracardiac origin. JAMA, 143, 870-872.

Cosgriff, S.W. (1953). Chronic anticoagulant therapy in recurrent embolism of cardiac origin. Ann Int Med, 38, 278-287.
Daley, R., Mattingly, T.W., Holt, C.L., Bland, E.F., and White, P.D. (1951). Systemic arterial embolism in rheumatic heart disease. Amer Heart J, 42, 566-581.

Darling, R.C., Austen, W.G., and Linton, R.R. (1967). Arterial embolism. Surg Gynec Obst, 124, 106-114.

Duff, I.F. (1950). The effectiveness of anticoagulant therapy as observed in 303 cases. Angiologica, 1, 170193.

Easton, J.D., and Sherman, D.G. (1980). Management of cerebral embolism of cardiac origin. Stroke, 11, 433-442.

Fisher, M., and Adams, R.D. (1951). Observations on brain embolism with special reference to the mechanism of hemorrhagic infarction. J. Neuropath Exp Neurol, 10, 92-93.

Fleming, H.A., and Bailey, S.M. (1971). Mitral valve disease, systemic embolism and anticoagulants. Postgrad Med J, 47, 599-604.

Foley, W.T. (1955). In transactions of a conference held under the auspices of the American Heart Association. Ed. Wright, I.S., and Luckey, E.H. Grune and Stratton. 153.

Frazier, S.H., Hill, N.C., Wakim, K.G., Sayre, G.P., Millikan, C.H., and Whisnant, J.P. (1957). Influence of anticoagulants on cerebral infarction produced by homologous blood clots. Proc Mayo Clin, 32, 717-722.

Furlan, A.J., Cavalier, S.J., Hobbs, R.E., and Weinstein, M.A. (1981). Risk of hemorrhage and timing of anticoagulation after non-septic embolic infarction. Neurology, 31 (2), 55-56.

Genton, E., Barnett, H.J.M., Fields, W.S., Gent, M., and Hoak, J.C. (1977). XIV cerebral ischemia: The role of thrombosis and of antithrombotic therapy. Study group on antithrombotic therapy. Stroke, 8, 150-175.

Hill, N.C., Millikan, C.H., Wakim, K.G., and Sayre, G.P. (1955). Studies in cerebrovascular disease. Experimental production of cerebral infarction by intracarotid injection of homologous blood clot, preliminary report. Proc Mayo Clin, 30, 625-633.

Howell, D.A., Tatlow, W.F.T., and Feldman, S. (1964). Observations on anticoagulant therapy in thromboembolic disease of the brain. CMAJ, 90,611-614.

Iizuka, J. (1972). Intracranial and infraspinal hematomas associated with anticoagulant therapy. Neurochirgia, 1, 15-25.

Marshall, J. (1976). The management of cerebrovascular disease. 3rd ed. Blackwell Scientific Publications, 112.

McDevitt, E., Carter, S.A., Gatje, B.W., Foley, W.T., and Wright, I.S. (1958). Use of anticoagulants in treatment of cerebral vascular disease. JAMA, 166, 592-597.

McDevitt, E. (1961). Anticoagulant therapy in cerebral vascular disease. Third conference. Ed. Millikan, C.H., Siekert, R.G., and Whisnant, J.P., Grune and Stratton, New York, 90-93.

Meyer, J.S. (1958). Localized changes in properties of the blood and effects of anticoagulant drugs in experimental cerebral infarction. NEJM, 258, 151-159.

Millikan, C.H. (1979). Anticoagulant therapy to prevent cerebral infarction. Med Clin N Amer, 63, 897-904. 
Moyes, P.D., Wakin, K.G., Sayre, G.P., and Millikan, C.H. (1955). Studies in cerebrovascular disease VI. Experimental cerebral infarction. A study of different techniques. Proc Mayo Clin, 30, 620-625.

Olsson, Y., Crowell, R.M., and Klatzo, I. (1971). The blood-brain barrier to protein tracers in focal cerebral ischemia and infarction caused by occlusion of the middle cerebral artery. Acta Neuropath, 18, 89-102.

Peterman, A.F., Wakim, K.G., Sayre, G.P., Whisnant, J.P., and Millikan, C.H. (1960). Effects of delayed anticoagulant therapy on experimental cerebral infarcts. J. Neuropath Exp Neurol, 18, 263-269.

Reichel, F. (1968). Anticoagulants and cerebral embolism. JAMA, 203, 59.

Sage, J.I., Van Uitert, R.L. and Duvoisin, R.C. (1981). Differences in mortality, morbidity and recurrence of cerebral ischemia in patients with atrial fibrillation on the basis of arteriosclerotic and rheumatic heart disease. Annals Neurology, 10, 104.

Sibley, W.A., Morledge, J.H., and Lapham, L.W. (1957). Experimental cerebral infarction. The effects of Dicumarol. Amer J. Med Sci, 234, 663-677.
Stephans, C.A.L. (1954). Anticoagulant therapy in private practice. Circulation, 9, 682-686.

Symonds, C. (1956). Cerebrovascular Accidents. Practitioner, 176, 130-136.

Szekely, P. (1964). Systemic embolism and anticoagulant prophylaxis in rheumatic heart disease. BMJ, 1, 1209 1212.

Vastola, E.F., and Frugh, A. (1959). Anticoagulants for occlusive cerebrovascular lesions. Neurology, 9, 143-148.

Wells, C.E. (1959). Cerebral embolism. The natural history, prognostic signs and effects of anticoagulation. AMA Archiv Neurol Psychiat, 81, 667-677.

Whisnant, J.P., Millikan, C.H., Sayre, G.P. and Wakim, K.G. (1959). Effect of anticoagulants on experimental cerebral infarction. Clinical implications. Circulation, 20, 56-65.

Wright, L.T., and Rothman, M. (1951). Deaths from Dicumarol. Arch Surg. 62, 23-28.

Case records of the Massachusetts General Hospital (1962). Ed. Castleman, B., and Kibee, B.U. NEJM, 267, 1085-1091. 